Acta Universitatis Wratislaviensis No 4053

Studia Linguistica XL Wrocław 2021

https://doi.org/10.19195/0137-1169.40.2

ELŻBIETA FLUDRA

ORCID: 0000-0002-3713-6943

Uniwersytet im. Adama Mickiewicza w Poznaniu, Польша

\title{
Эвфемизмы семантического поля секс в русском и польском языках с точки зрения их прямых значений
}

\section{Введение}

В ходе повседневного общения люди очень часто - сознательно или подсознательно - избегают употребления слов и выражений, считающихся неприличными или неуместными. Говорящий имеет возможность либо вообще не произносить их вслух, либо говорить о них не прямо, а с помощью других слов, под которыми подразумеваются эвфемизмы. Как замечает Д. Рембишевска, в лингвистике не существует общепринятых критериев определения данного понятия (Rembiszewska 2008:69, за Szymczak-Rozlach 2014:66). B результате этого термин эвфемизм трактуется и понимается учеными по-разному. Рассмотрение его дефиниций, существующих на сегодняшний день в научном обороте, выходит, однако, за рамки настоящей статьи. В связи с тем ограничимся лишь указанием наиболее значимых работ в области исследования эвфемизмов. Из трудов польских лингвистов нельзя не привести научного наследия А. Домбровской (Dąbrowska 1993, 1998) и К. Дембской (Dembska 2001, 2002a, 2002b, 2007). Среди работ русских языковедов внимания, несомненно, заслуживают труды В. П. Москвина (Москвин 1999, 2001) и Е. П. Сеничкиной (Сеничкина 2006, 2008).

В настоящем исследовании исходим из понимания эвфемизма, представленного в словаре Катажины Дембской, согласно которому под эвфемизмом подразумевается лексическая единица, маскирующая и одновременно смягчающая суть высказывания. Чаще всего она выступает либо как одно- или двухэлементная, либо в виде фразеологического оборота. По словам ученой, эвфемизмы остаются с заменяемыми ими выражениями либо в синонимиче- 
ских, либо в квазисинонимических отношениях. Сверх того, они, во-первых, осознаются носителями языка, даже если взяты вне контекста (по крайней мере представителями одной социальной группы), во-вторых, зафиксированы в словарях (хотя бы в жаргонных). Слова, выступающие в высказывании в роли эвфемизмов, но не ассоциирующиеся у носителей языка с конкретным денотатом вне контекста, называются контекстуальными (Dembska 2007:12).

Несмотря на широкое использование эвфемистических выражений как в русском, так и в польском языках, можно выделить две основные сферы их применения: обиходно-бытовую и социально-политическую (Markunas 2010:5, Ковшова 2007:72). Согласно М. Л. Ковшовой, названные области эвфемизации отличаются в основном причинами непрямого наименования. Обиходно-бытовые эвфемизмы, относящиеся к семейной, интимной и повседневной сферам человеческой жизни, употребляются с целью «этикетно-этического смягчения неприятного в речи», в то время как специфика социально-политических заключается в языковой манипуляции (Ковшова 2007:72-73).

В настоящей статье анализу подвергаются принадлежащие к обиходно-бытовой сфере эвфемизмы семантического поля секс. Выбор данного поля обусловлен тем, что оно относительно редко становится предметом исследований лингвистов, хотя подвергается процессу эвфемизации как одно из самых распространенных. По нашим наблюдениям, самую высокую активность в рамках названной тематики среди польских и русских языковедов проявляет ранее упомянутая польская ученая К. Дембска. Внимания заслуживают также работы Зузанны Крутки (Krótki 2014), Малгожаты Брошко (Broszko 2017) и Ярослава Пацулы (Pacuła 2020a, 2020b).

Цель статьи заключается в распределении эвфемизмов по группам в соответствии с их прямыми значениями в русско-польском сопоставительном аспекте. Источником материала послужили «Rosyjsko-polski słownik eufemizmów semantycznego pola seksu» («Русско-польский словарь эвфемизмов семантического поля секс») К. Дембской и «Rosyjsko-polski dydaktyczny słownik podstawowych eufemizmów» («Русско-польский дидактический словарь основных эвфемизмов») А. Маркунаса. В исследовании учитывались эвфемизмы (в том числе контекстуальные), заменяющие следующие наименования: половой акт, совершать/совершить половой акт, мужской половой орган, яички, женские половые органы, ягодицы, женская грудь, проститутка. Выбор данных наименований обусловлен тем, что они формируют ядро и ближайшую периферию рассматриваемого семантического поля (Dembska 2007:221-222). В число анализируемых лексических единиц вошло 368 эвфемизмов русского языка и 94 польского ${ }^{1}$. Собранный материал был разделен

1 В случае, если какой-либо эвфемизм вбирает в себя дополнительный семантический оттенок, то рядом с ним приводится дефиниция. 
на четыре семантические группы в соответствии с тематической соотнесенностью прямого значения. Учитывая тот факт, что число эвфемизмов в русском языке почти в четыре раза выше, чем в польском, результаты анализа будут сопоставляться в процентных соотношениях, подсчитанных отдельно для каждого языка.

Следует подчеркнуть, что статья не претендует на все исчерпывающее исследование указанной проблематики. В рамках настоящего исследования возможно, во-первых, подвергнуть анализу наименования, находящиеся в зоне дальнейшей периферии, во-вторых, выделить другие менее многочисленные группы прямых значений с учетом других признаков.

\section{Основная часть}

В обоих языках выделяется группа эвфемизмов, прямые значения которых отсылают к миру природы. В русском языке их удельный вес составляет четверть от общего числа всех рассматриваемых единиц, в польском - на $8 \%$ меньше. Здесь наиболее широко представлены эвфемизмы, именующие женщину легкого поведения и мужской половой орган. Преобладающее большинство из них построено на метафорическом переносе наименования животного:

русск. 'проститутка' - вол, выхухоль, жаба, жучка, кобра, кобыла, кошка, ласточка, лебеди, мартышка, ночная бабочка, рыбка хариус, телка, хорек, чайка и др.;

польск. 'проститутка' - jałówka, kaczka, kobyła, larwa, mewa, mewka, matpa, matpka, nocny motyl;

русск. 'мужской половой орган' - анаконда, барсик, воробушек, головастик, гусь, зяблик, козел на привязи, петушок, попугай, поросенок ('мужской половой орган больших размеров'), птичка, рыбка ('мужской половой орган, скорее всего, небольшого размера)', слон ('мужской половой орган больших размеров'), соловей, хариус, хомяк, иыпленок, червяк, чиж, ящерииа и др.;

польск. ‘мужской половой орган' - kurczę, robaczek, wróbelek.

В русском и польском языках значение 'мужского полового органа' передается также при помощи слов, обозначающих подвижный придаток на задней части тела животного, ср. рус. хвостик и пушистый хвостик, польск. ogon и ogonek. Кроме вышеперечисленных обозначений в польском языке был также обнаружен еще один эвфемизм, не входящий в данную группу. Речь идет о лексеме $k w i a t^{2}$, заменяющей наименование мужского полового органа.

2 Эвфемизм kwiat употребляется также для обозначения женских половых органов. 
Прямые значения, связанные с миром растений, более характерны для русского языка. Вместо слова проститутка употребляются такие эвфемистические варианты, как лимонка, маргаритка ('женщина, оказывающая услуги по оральному половому акту'), фисташка ('несовершеннолетняя проститутка, специализирующаяся на оказании услуг по оральному половому акту') и шала. В свою очередь, наименования мужского полового органа пополняются за счет следующих лексем: анютина глазка ('мужской половой орган небольшого размера'), артишок ('мужской половой орган небольшого размера'), ночная фиалка, пенек, пенчик, пень, турнепс, тычинка, фрукт, хрен, иветок. Сверх того, в русском языке зафиксирован один эвфемизм, который относится к наименованию гриба (подосиновик). Вбирает он в себя семантическое значение 'мужской половой орган'.

Среди эвфемизмов, прямые значения которых отсылают к миру природы, отмечены также наименования женских половых органов, причем в польском языке лишь один - вышеупомянутый $k$ wiat. Все русские эвфемистические выражения, принадлежащие данной группе, заменяются либо наименованием животного (жучка, королек, соловей), либо наименованием растения (мохнатая роза любви, розочка, цветок, цветок жизни, эдельвейс). Кроме того, посредством переноса названий животных и растений образуются выступающие исключительно в русском языке эвфемизмы, которые обозначают половой акт и ягодицы. Первые именуются с помощью таких слов и выражений, как бесчеремуха ('половой акт без высших чувств') ${ }^{3}$, земляничка, клубничка, ромашка ('вид группового полового акта, когда его участники сидят в круге наподобие лепестков ромашки'), птенчик в гнездылико, хомячок в норку, вторые - с помощью лексем попугай и соловей.

В пределах обсуждаемых ныне прямых значений выделяется небольшая группа эвфемизмов русского языка, которые вбирают в себя значение 'совершить (совершать) половой акт'. К ним относятся следующие: кобылку купить идти/пойти, обсеменить кого-л., отпетухать кого-л. ('совершить гомосексуальный половой акт (часто с применением насилия)'), napumb корягу, петушить кого-л. ('совершать анальный половой акт, чаще всего с применением насилия').

Вторую группу прямых значений составляет лексика, отсылающая к сходству формы и цвета. Она получила особое распространение в польском языке, в котором ее удельный вес от общего числа эвфемизмов превышает $50 \%$, являясь тем самым наиболее многочисленной группой. В русском общее количество обсуждаемых лексем достигает $24 \%$, составляя третий по объему разряд. В обоих языках подавляющее большинство данных эвфемизмов $-64 \%$ в русском и $62 \%$ в польском - относится к наименованию мужского полового органа. Среди них вместо нежелательного слова чаще всего

3 Эвфемизм бесчеремуха образован от имени существительного черемуха. 
употребляется техническая терминология, например: русск. болт, напильник, пистолет, пистон, свайка, царь-пушка, шомпол; польск. armata, gwóźdź, hak, kotek, lufa, pistolet, wycior.

Кроме того, обращает на себя внимание лексика, связанная с едой, в пределах которой чуть ли не все лексемы русского и польского языков объединяются в эквивалентные пары, ср. банан-banan ${ }^{4}$, морковка-marchewka, oгypeu-ogórek, колбасa-kiełbasa, сосиска-parówka. Прямые значения, относящиеся к лексико-семантическому полю еды, довольно часто встречаются в группе эвфемизмов, именующих яичка. В русском они заменяются такими словами, как абрикосы, кокосы, орехи, помидоры, яйца, в польском jaja и orzechy. Для обозначения яичек используются также названия музыкальных инструментов: бубенщь и бубенчики, польск. $d z w o n k i$ и $d z w o n e c z k i$.

В пределах прямых значений, отсылающих к сходству формы, обнаружены также слова, содержащие в своем лексическом составе сему «отверстие». Наиболее широко они представлены среди наименований женских половых органов. Как и рассмотренные ранее, данные слова также объединяются в эквивалентные пары: дупло-dziupla, дыра-dziura, дырка-dziurka, нора-nоra, норка-norka, щелка-szparka, щель-szpara. Наличие данной семы отмечается также в эвфемизмах, называющих ягодицы, и анус, в основе образования которых лежит прием синекдохи, ср. русск. труба и трубка, польск. rura.

Эвфемизмы, образованные на сходстве по цвету, обнаружены исключительно в пределах наименований русского языка, вбирающих в себя семантическое значение 'совершать/совершить половой акт'. Речь идет о таких выражениях, как шоколадка ('совершение анального, а затем орального полового акта'), доставать шоколад ('совершать анальный половой акт'), раскупорить шоколадку ('совершить анальный половой акт'), стучать в шоколадку ('совершать анальный половой акт'), заехать в коричневое ('совершить анальный половой акт').

В обоих языках небольшие группы в рамках рассматриваемых эвфемизмов составляют наименования полового акта (ср. русск. палка и штылковая aтака; польск. patka) и женской груди (ср. русск. ананас, банки, фapbl, шарики; польск. bańki, kule, kulki).

В третьей тематической группе зафиксированы эвфемизмы, прямые значения которых отсылают к сходству действия. В русском языке их удельный вес достигает $37 \%$, составляя самую репрезентативную группу, в польском $31 \%$, что образует вторую по объему группу. Названные прямые значения наиболее частотны, конечно, среди наименований, обозначающих соверше-

4 Несмотря на то, что названия фруктов и овощей можно отнести к миру природы, то, однако, в данных случаях в основе переноса их значений на наименования, принадлежащие семантическому полю секс, скорее всего, лежит сходство формы. 
ние полового акта, которые в плане обоих языков объединяются следующими семами:

1. «поместить внутрь чего-л.»

русск. вставить пистон кому-л., вдолбить кому-л., впрыснуть (в прелки) кому-л., всадить кому-л., забить пулю (сваю) кому-л., запустить (дурашку) кому-л. и др.

польск. wsadzić komuś, wsunać komuś, wtykać komuś.

2. «переместить что-л., толкая»

русск. двигать мебель, перепихнуться с кем-л., пихать кого-л., пихать ся с кем-л.

польск. pchać kogoś, pchać się z kimś, popychać kogoś, przepchną́ kogoś.

3. «резким движением заставить переместиться»

русск. дернуть кого-л., толкать кого-л., толкаться с кем-л.

польск. szarpnąć kogoś.

4. «прийти в соприкосновение»

русск. связываться с кем-л., соединяться с кем-л., стыковаться с кем-л., схлестывваться с кем-л.

польск. taczyć się z kimś.

5. «приводить в колебательное движение»

русск. качать кого-л., колебать кого-л., махаться с кем-л. польск. huśtać kogoś.

В русском языке довольно часто отмечаются также лексические единицы, отсылающие к семантическому значению глагола сунуть, напр.: втылкать кому-л., всунуть кому-л., задвинуть кому-л.

Следующей наиболее сближенной в процентном соотношении группой наименований в пределах рассматриваемых эвфемизмов являются названия полового акта (в русском языке их удельный вес составляет $11 \%$, в польском - 10\%). Здесь среди русских эвфемистических выражений чаще всего встречаются лексемы, прямые значения которых связаны с процессом втягивания в рот и проведения языком по чему-нибудь, ср. лекара ${ }^{5}$, oтcoc, cocaль, чуnа-чуnс. Все они вбирают в себя семантическое значение 'оральный половой акт'. Более того, наименования полового акта заменяются лексемами, содержащими в своем значении вышеобсуждаемые семы, ср. «переместить что-л., толкая»: перепихнин, перепихон и перепихон (перепихнин) с повторином ('два половых акта, совершенных один за другим'); «колебательное движение»: качай-качай и качели с висом ('половой акт, совершаемый стоя'). Обозначение позиции при половом акте находит также отражение в таких эвфемизмах, как ламбада ('половой акт, совершаемый во время медленного танца') и в (на) стояка ('половой акт, совершаемый стоя'). В польском языке

5 Эвфемизм лекара образован от английского to lick ('лизать'). 
рассматриваемая группа прямых значений насчитывает три единицы, в том числе две эквивалентные русским: na stojaka ('половой акт, совершаемый стоя'), odsysanie ('оральный половой акт'), połaczenie.

Кроме того, в исследованном материале обнаружены выступающие исключительно в русском языке эвфемизмы, именующие мужской половой орган, проститутку и женскую грудь. Среди первых преобладают прямые значения, обозначающие положение в пространстве, ср. ванька-встанька ('легко возбуждающийся мужской половой орган'), висячий, стоячка, торч, торчила/торчило ('мужской половой орган (чаще всего во время эрекции)'), торчун. Группа наименований проституток неоднородна, в ее пределах возможно объединить лишь две лексемы, прямые значения которых отсылают к действию, выполняемому ртом: жвачка ('проститутка, предпочитающая оральный секс'), (ночная) соска ('женщина, оказывающая свои услуги по оральному половому акту’). Кроме них отмечены такие эвфемизмы, как волочайка, повалюшка, целлялка ('уличная проститутка'). В свою очередь, названия женской груди заменяются словами, которые вбирают в себя значения, упомянутые ранее, ср. вислихи и кольхание.

Среди обсуждаемых прямых значений в обоих языках единичными примерами представлены наименования ягодиц: русск. курсанка ('ягодицы, анус' $)^{6}$, седло, сиделище/седалище, сиделка; польск. siodto.

Единицы последней по численности группы эвфемизмов вбирают в себя прямые значения, относящиеся к омонимам. Причем следует подчеркнуть, что в польском языке они составляют лишь 1\% от общего числа рассматриваемых лексем. В русском удельный вес названных эвфемистических выражений составляет $14 \%$, а в его пределах самой многочисленной группой являются наименования мужского полового органа, прямые значения которых разделяются на следующие подгруппы:

1. персонажи: буратино, карлсон, мужичок с ноготок ('мужской половой орган небольшого размера'), полкан, тарзан, фантомас, фанфантюльпан, фома годеев, франкенштейн, хрюша, чебурашка, итирлищ;

2. личные имена: абдула, абрамка, василий(алибабаевич), ямка;

3. реальные люди: гамсахурдия, карл маркс, павло тычина, первопечатник федоров, хасбулатов, христофор колумб, цукерман, ясир арафат;

4. топонимы: эйфелева башня, биг-бен ('мужской половой орган больших размеров'), гондурас.

Вторую по объему группу составляют названия проституток. Здесь непрямое наименование нежелательного денотата реализуется исключительно с помощью личных имен, ср. лаура, маруся, маруха, марушка, марьяна, машка, наташа, синди. Прямые значения, отсылающие к личным именам,

6 Эвфемизм курсанка образован от жаргонного слова курсать - ‘испражняться’. 
встречаются также среди наименований женских половых органов (люся и машка в русском языке, marysieńka - в польском) и полового акта (магдалина и моника). Кроме того, в группе эвфемизмов, обозначающих половой акт, отмечены лексемы, называющие реальных людей: лаиса и мессалина: географические объекты: версаль ('гомосексуальный половой акт'), роттердам ('оральный половой акт') и персонажей: сулико ('гомосексуальный половой акт’). Единичными примерами представлены также эвфемизмы, вбирающие в себя значение 'совершать половой акт', ср. ехать в роттердам ('совершать оральный половой акт'), чебурашить кого-л. и чебурашиться с кем-л.

\section{Заключение}

Итак, в результате проведенного анализа было выявлено, что прямые значения русских и польских эвфемизмов семантического поля секс объединяются в сходные группы, что позволяет сделать вывод об одинаковых когнитивных основах номинативных пространств в исследуемых славянских языках. Отличительные черты обнаруживаются в неодинаковом количественном соотношении заменяемых наименований в рамках отдельных групп, среди которых наименее сближенными оказались прямые значения, отсылающие к омонимам, а наиболее - прямые значения, отсылающие к сходству действия. В заключение следует подчеркнуть, что представленное исследование носит фрагментарный характер, в связи с чем данный вопрос требует дальнейшего рассмотрения.

\section{Библиография}

Broszko Małgorzata, 2017, Jak dzyndzyk z nici w kłębek ułożonych stał się nazwą męskiego członka - analiza historycznojęzykowa wybranych nazw narządów płciowych w polszczyźnie, в: [v:] Studia Filologiczne Uniwersytetu Jana Kochanowskiego 30, c. [s.] 37-49.

DĄBRowsKa Anna, 1993, Eufemizmy współczesnego języka polskiego, Wrocław.

DĄBRowska Anna, 1998, Słownik eufemizmów polskich: czyli w rzeczy mocno, w sposobie łagodnie, Warszawa.

Dembska Katarzyna, 2001, Eufemizm - problemy badawcze (na materiale języka rosyjskiego), B: [v:] Przegląd Rusycystyczny 1, c. [s.] 68-71.

Dembska Katarzyna, 2002a, Krótka charakterystyka zjawiska eufemizacji we współczesnym języku rosyjskim (na przykładzie pola semantycznego seksu), в: [v:] Łuczków I./Sokołowski J. (ред. [red.]), Wyraz i zdanie w językach słowiańskich. Opis - konfrontacja - przekład, Wrocław, c. [s.] 71-75.

Dembska Katarzyna, 2002b, Metaforyczny charakter wyrażeń eufemistycznych współczesnego języka rosyjskiego (na przykładzie pola semantycznego seksu), в: [v:] Przegląd Rusycystyczny 1 , c. [s.] 116-120.

Dembska Katarzyna, 2007, Rosyjsko-polski słownik eufemizmów semantycznego pola seksu, Toruń. 
KRóTKı Zuzanna, 2014, Eufemistyczne nazwy stosunku seksualnego w historii języka polskiego, в: [v:] Przyklenk J. (ред. [red.]), Bogactwo polszczyzny w świetle jej historii, т. [t.] 5, Katowice, c. [s.] $140-153$.

MarkUnAS Antoni, 2010, Rosyjsko-polski dydaktyczny słownik podstawowych eufemizmów, Poznań.

PACUlA Jarosław, 2020a, Leksyka dotycząca „najstarszego zawodu świata” w polskim socjolekcie przestępczym z XIX i początku XX wieku, в: [v:] Studia Linguistica 39, c. [s.] 127-150.

PACulA Jarosław, 2020b, Z historii polskiego słownictwa erotycznego - nazwy intymnych części ciała w dawnym socjolekcie przestępczym, в: [v:] Annales Universitatis Paedagogicae Cracoviensis. Studia Linguistica 15, c. [s.] 163-178.

Rembiszewska Dorota Krystyna, 2008, Eufemizmy w Słowniku dialektu knyszyńskiego Czesława Kudzinowskiego, в: [v:] Czyżewski F./Tyrpa А. (ред. [red.]), Tabu językowe i eufemizacja w dialektach słowiańskich, Lublin, c. [s.] 69-77.

SzymCZaK-Rozlach Mariola, 2014, Eufemizmy we współczesnym języku słowackim, Katowice.

Ковшова Мария Львовна, 2007, Семантика и прагматика эвфемизмов: краткий тематический словарь современных русских эвфемизмов, Москва [Kovšova Mariâ L'vovna, 2007, Semantika i pragmatika: kratkij tematičeskij slovar' sovremennyh russkih èvfemizmov, Moskva].

Москвин Василий Павлович, 1999, Эвфемизмы в лексической системе современногорусского языка, Волгоград [Moskvin Vasilij Pavlovič, 1999, Èvfemizmy v leksičeskoj sisteme sovremennogo russkogo âzyka, Volgograd].

Москвин Василий Павлович, 2001, Эвфемизмы: системные связи, функции и способы образования, в: Вопросы языкознания 3, с. 58-70 [Moskvin Vasilij Pavlovič, 2001, Èvfemizmy: sistemnye svâzi, funkcii i sposoby obrazovaniâ, v: Voprosy âzykoznaniâ 3, s. 58-70].

Сеничкина Елена Павловна, 2006, Эвфемизмы русского языка: спецкурс: учеб. пособие, Москва [Seničkina Elena Pavlovna, 2006, Èvfemizmy russkogo âzyka: speckurs: učeb. posobie, Moskva].

Сеничкина Елена Павловна, 2008, Словарь эвфемизмов русского языка, Москва [Seničkina Elena Pavlovna, 2008, Slovar' èvfemizmov russkogo âzyka, Moskva].

\section{Euphemisms related to the semantic field of sex in Russian and Polish from the point of view of their basic meanings}

The aim of this article is to compare the basic meanings of Russian and Polish euphemisms from the semantic field of sex. Eight areas of this field were examined: the terms for the sexual act, the male sex organ, testicles, the female sex organ, buttocks, breasts, and prostitutes. Along with the area of the sexual act, a separate meaning for 'engaging in a sexual activity' has been differentiated. The analysis showed that the basic meanings are divided into the same groups in both languages, which allows us to conclude that euphemisms from the semantic field of sex in Russian and Polish are created based on similar cognitive foundations.

Keywords: euphemism, sex, sexual act, basic meanings. 